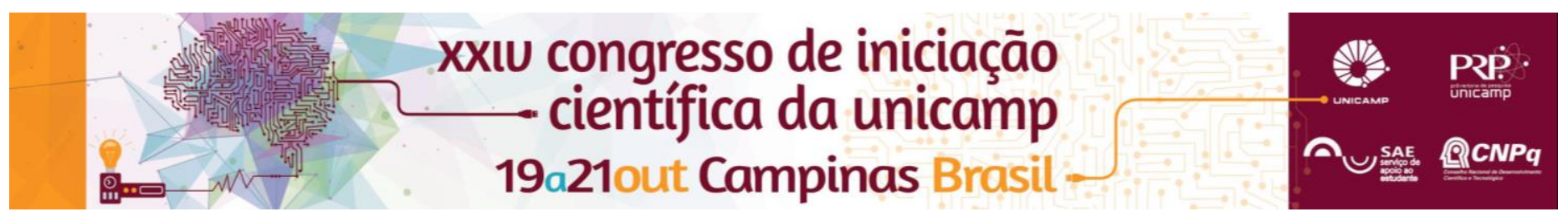

\title{
Medidas de Excitação Plasmônica em Filmes de Ouro e de Prata
}

\author{
Wanderléia D Dias *, Dayane S Bancoff, René A Nome, Cristiano M B Cordeiro.
}

\section{Resumo}

O presente projeto consiste no estudo da depência da excitação de plasmon com o ângulo de incidência ou com o comprimento de onda em filmes finos metálicos utilizando a configuração Kretschmann. Estudo da sensibilidade do sensor com a alteração do índice de refração do meio externo está em andamento.

\section{Palavras-chave:}

Plasmon, filme fino, sensor índice de refração.

\section{Introdução}

Plasmônica é um campo da ciência que estuda a interação de radiação eletromagnética com os elétrons livres em uma superfície metálica. No caso de filmes finos metálicos o método experimental mais utilizado para excitação óptica de plasmons é a configuração de Kretschman que utiliza vetor de onda viajando em meio dielétrico como o vidro, para excitar o movimento eletrônico na interface metal / meio externo (ar, líquido etc). A montagem utilizada para esse método se baseia em uma fonte de luz polarizada que incide em um prisma com uma superfície metálica enquanto o sinal refletido é caracterizado com um detetor ou espectrômetro. Podemos reconhecer a excitação do modo plasmônico observando um vale na curva de refletividade (figs 1 e 2).

A técnica de excitação plasmônica pode ser empregada para estudos de fenômenos de superfície, monitorando a medida da mudança de índice de refração Por ser capaz de fazer este monitoramento ela vem sendo utilizada no desenvolvimento de sensores ópticos.

O objetivo deste trabalho é fazer testes em amostras volumétricas para desenvolver sensores plasmônicos baseados na mudança de índice de refração.

\section{Resultados e Discussão}

A configuração experimental consiste de uma fonte de espectro visível $(400 \mathrm{~nm}-800 \mathrm{~nm})$ para as medidas de comprimento de onda variável e um laser de $\mathrm{He}-\mathrm{Ne}$ em 543 ou $633 \mathrm{~nm}$ para as medidas em que variamos o ângulo de incidência. As amostras utilizadas são baseadas em um semi-cilindro de vidro BK-7 com filme nanométrico de ouro sobre camada de adesão de titânio ou cromo e outro com filme de prata.

As medidas da refletividade versus ângulo de incidência foram realizadas com laser com polarização $p$. Sinal medido pelo detector era adquirido por um computador que também controlava a rotação da amostra com passo mínimo de 0,005 graus. Figura 1 mostra resultados típicos para a amostra com ouro (lado esquerdo) e prata (lado direito) ao se mudar o meio externo ao filme metálico. Neste caso as amostras tem espessuras nominais de $30 \mathrm{~nm}$ ouro sobre $3 \mathrm{~nm}$ titânio (fig.1a) e $50 \mathrm{~nm}$ de prata (fig.1b). Medidas experimentais destas espessuras estão sendo realizadas pelo grupo [1]

Nota-se que o aumento do índice de refração de ar para água e álcool desloca o ponto de mínima refletância - ângulo de excitação de plásmon - para maiores ângulos. a)

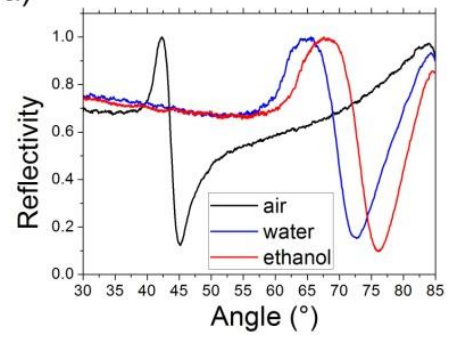

b)

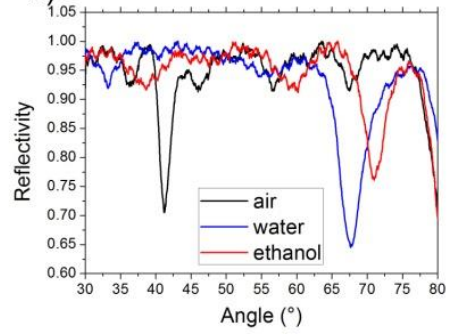

Figura 1. Refletância versus ângulo de incidência para filmes em três diferentes meios externos. A) filme de Ouro B) filme de Prata

Em outro tipo de medida com as mesmas amostras mostradas na figura 1a o ângulo foi mantido fixo e com valor maior do que ângulo crítico de reflexão interna total. Uma fonte de luz branca foi utilizada para medidas de refletância versus comprimento de onda. Figura 2 mostra um resultado típico desta caracterização.

Comparação de dados experimentais com simulações analíticas estão sendo realizadas pela mestranda Dayane Bancoff.

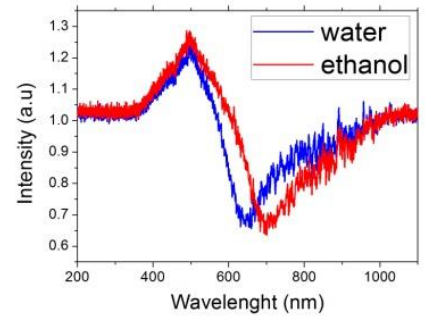

Figura 2 Refletância versus comprimento de onda para ângulo de incidência de $73^{\circ}$ graus.

\section{Conclusões}

Verificamos a excitação plasmônica em filmes de ouro e de prata variando o comprimento de onda e o ângulo de incidência. Fizemos medidas variando índice de refração externo utilizando água e etanol. Os dados levantados até o momento servirão de base para desenvolver um sensor formado com fibra óptica.

\section{Agradecimentos}

Este trabalho é financiado pela Fapesp via projeto \#2014/50632-6. Agradecemos ao SAE/Unicamp pela bolsa fornecida.

[1] FIGUEIREDO, I. C; OSÓRIO J.H; BANCOFF D. S.; CORDEIRO C.M.B. Optical measurement of a thin metal film and the study of surface of plamon resonance in a metal coated tapered fiber. In XXIV Congresso de Iniciação Científica da Unicamp, 2016 